\title{
FACTORS INFLUENCING RECRUITMENT TO A SCHOOL-BASED TRIAL OF A TARGETED INTERVENTION TO PROMOTE EXERCISE SELF-EFFICACY IN CHILDREN WITH RISK FACTORS FOR OBESITY
}

\author{
C. Glazebrook ${ }^{1}$, N. Mullen ${ }^{1}$, L. McWilliams ${ }^{1}$, M. Batty ${ }^{1}$, L. Hogarth ${ }^{1}$, I. Macdonald ${ }^{1}$, A. Smyth ${ }^{1}$, D. Nathan ${ }^{2}$ \\ ${ }^{1}$ Psychiatry, University of Nottingham, ${ }^{2}$ Child Health, Queens Medical Centre, Nottingham, UK
}

Background and aims: Reducing levels of sedentary behaviour is an important strategy to reduce risks of obesity. Children with asthma often avoid active games and low levels of confidence in relation to physical activity (exercise self efficacy) is another barrier to effective participation in physical education. This study aims to explore factors influencing recruitment to a targeted, school-based activity programme designed to increase confidence about exercise and levels of physical activity in primary school children.

Method: Children aged 9 to 11 in 12 schools were screened for teacher-rated overweight using a validated scale and for child-rated low self-efficacy and asthma. Active children were excluded from the study. Overweight children ( $\Rightarrow>91$ st centile), those with low exercise self-efficacy and children with asthma were invited to participate in a cluster randomised trial of Steps to Active Kids (STAK). STAK is a school-based programme to increase exercise self-efficacy through a stepped programme including activity diary, street dance DVD, circuit training, motivational interviewing and goal setting.

Results: Of 1087 children screened 447 (41\%) met the inclusion criteria and $180(40 \%)$ consented to participate. Participating children were heavier than non-responders $(\mathrm{p}=0.015)$, with $55 \%$ in the top BMI centile joining the study, but they had very similar levels of exercise self-efficacy and rates of asthma. Strategies to enhance uptake of the study have increased recruitment rates from $35 \%$ in phase 1 to $51 \%$ in phase 3.

Conclusion: Overweight, low exercise self-efficacy and asthma are not barriers to participation in a study to increase physical activity. 